\title{
Role of Water in Magma Generation and Initiation of Diapiric Uprise in the Mantle
}

\author{
Peter J. WyLlie \\ Department of Geophysical Sciences, University of Chicago, Chicago, Illinois $606 \$ 7$
}

\begin{abstract}
The content and distribution of water is a critical factor in determining mantle properties, especially in the low-velocity and Benioff zones. Estimated temperature distributions vary widely, depending on assumptions regarding the relative significance for heat transfer of conduction, radiation, and convection. Comparison of estimated geotherms with known or inferred phase relationships in the system peridotite-eclogite-water provides information about the possible physical state of the mantle at various depths for comparison with geophysical measurements. Water is stabilized in minerals such as amphibole and phlogopite in the upper mantle; at greater depths, it may exist as intergranular fluid probably adsorbed on mineral surfaces, or it is dissolved in interstitial silicate magma. The most satisfactory explanation for the low-velocity zone involves incipient melting due to traces of water. Water rising from the deep mantle in preferred zones would augment the interstitial silicate magma at the base of the low-velocity zone, initiating the diapiric uprise necessary for basaltic magma generation. A petrological model for the suboceanic mantle suggests that a lens of gabbro-rich material may account for the gravity anomaly and seismic refraction measurements at mid-oceanic ridges. A petrological model for the area beneath island ares suggests that the seismic lowvelority zone should not be continuous across it. Magma may be generated beneath island ares by partial fusion of down-going oceanic crust by frictional heating, by migration of water from the lithosphere into overlying mantle, or by diapiric uprise of material from the downgoing lithosphere. Diapiric uprise could be initiated by influx of water into the layer including the mantle-upper lithosphere boundary over a down-going slab. The composition of the liquid generated depends on many variables, including the water content and the stability of hydrous minerals. Magma generation may depend on the regime of water, rising from the deep montle in preferred zones and carried down with the lithosphere in Benioff zones.
\end{abstract}

For consideration of magma generation in the mantle, we need to know the temperature distribution, the mantle composition, and the properties of the mantle material. These parameters remain uncertain.

Figure 1 shows three estimated temperature distributions; these vary, depending on assumptions as to the relevant significance for heat transfer of conduction, radiation, and convection. At $500 \mathrm{~km}$ depth, there is a difference of about $1000^{\circ} \mathrm{C}$ between the uppermost and lowest curves. According to recent reviews [Ringwood, 1969a; Wyllie, 1970], the upper mantle is composed of peridotite and eclogite, possibly with traces of water and carbon dioxide. The relevant mantle property for magma generation is the melting temperature. Solidus curves have been measured experimentally up to pressures corresponding to about $150 \mathrm{~km}$

Copyright () 1971 by the American Geophysical Union. depth; solid lines in Figure 1 to 100-km depth show the range of reported curves. These limits are extrapolated linearly to $500 \mathrm{~km}$, and an indication of the area of uncertainty is shown by the shaded band.

According to these estimates of temperature distribution and melting temperatures, magma does not form in dry mantle under normal conditions. Of the many mechanisms proposed to raise the temperature above the solidus, the most reasonable model is that involving diapiric uprise of solid mantle [Green and Ringwood, 1967]. I examine here the effect of water on the conditions for melting in the mantle, and on the model of diapiric uprise. To illustrate patterns of behavior of mantle materials, I shail arbitrarily adopt the oceanic geotherm from Figure 1, and the line drawn within the shaded band for the solidus.

The amphibole and phlogopite in mantle-derived eclogite and peridotite nodules in kimber- 
bite has been cited as evidence for water in the mentle (see review by Wyllie [1970]). G. C. Bennedy (personal communication, 1970) contends that this evidence has been misinterpreted because the hydrous minerals occur only in the outer parts of nodules, as late alteration products. Nevertheless, the effects of even traces of water in the mantle are so significant that we must evaluate them. Water was certainly present in the mantle at some earlier stage of its history, and according to the new global tectanics it is probably being carried down into the mantle beneath island ares [Isacks et al., 1968].

\section{Petrology of the Mantle}

Phase diagrams for mantle materials show the mineral facies, and the mantle mineralogy at any depth is given by following geotherms through the facies.

Phase diagrams for peridotite-eclogite-water. Figures 2 and 3 illustrate schematically the phase relationships in peridotite and gabbro up to pressures corresponding to $600 \mathrm{~km}$ depth; these diagrams were obtained by combination of and extrapolation from experimental results. Each diagram has the solidus from Figure 1; peridotite has a wide melting interval, but gabbro and eclogite have a narrow melting interval. Two subsolidus transformation intervals are shown for each rock.

With increasing pressure, feldspathic peridotite transforms to spinel peridotite and then to gamet peridotite; this transformation is accomplished through the low-pressure shaded band. Gamet peridotite persists to the high-pressure shaded band, where olivine is transformed into a spinel-like phase and the pyroxene dissolves in the garnet [Ringwood, 1969b]. Phase transitions occurring at greater pressures are not shown. In Figure 3, the transformation of gabbro to eclogite is shown by the low-pressure shaded band, and by analogy with Figure 2 it is assumed that the pyroxene dissolves in the garnet through the high-pressure shaded transformation interval.

Figure 4 compares the phase relationships in dry gabbroic material with those in the presence of excess water to pressures corresponding to $100-\mathrm{km}$ depth. The effect of adding excess water is to: (1) lower (initially) the temperature of beginning of melting, (2) increase the melting interval, and (3) introduce a hydrous mineral,

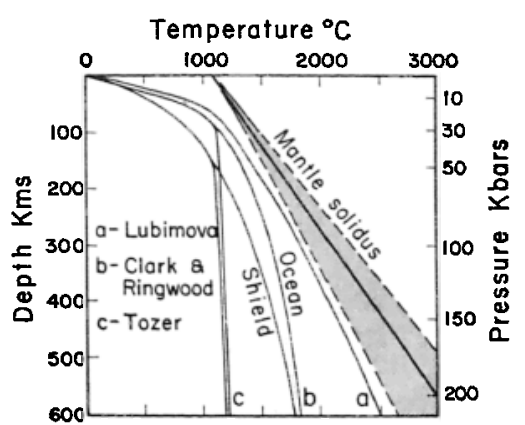

Fig. 1. Estimated geotherms for a conduction model [after Lubimnva. 1967]. a conductionradiation model [Clark and Ringrood, 1964], and a convection model [Tozer, 1967]. Curves $b$ were calculated to $400 \mathrm{~km}$ by Clark and Ringwood, and extended to $1400 \mathrm{~km}$ by Tozer. Experimentally determined solidus curves for peridotites and eclogites lie within the two solid lines extending to about 100-km depth [Green and Ringwood, 1967, 1963; Cohen et al., 1967; Ito and Kennedy, 1967, 1968; Kushiro et al., 1968]. The shaded band gives an idea of the range of uncertainty in extrapolating the mantle solidus to $600 \mathrm{~km}$ depth. The line within this band is adopted arbitrarily in following diagrams.

amphibole, which becomes stable with liquid. At about $15-\mathrm{kb}$ pressure, the plagioclase feldspar breaks down, and the slope of the solidus $(d P / d T)$ changes from negative to positive. Its slope becomes similar to that of the solidus for the dry eclogite. Similarly, as amphibole breaks down to yield garnet at pressures above about $15 \mathrm{~kb}$, the slope of its breakdown curve reverses so that it passes below the solidus curve at about $25 \mathrm{~kb}$. The gabbro-eclogite phase transition is masked within the stability field of amphibole.

The general pattern of the phase relationships for gabbro in the presence of a trace of water can be deduced from Figure 4 [Lambert and Wyllie, 1970b; Wyllie, 1970], and the result is shown in Figure 5. This isoplethal section for a gabbro-water mixture with insufficient water present to saturate the rock shows that all the water is stored in the amphibole within its stability field. The solidus between 1 and $25 \mathrm{~kb}$ is given by the curve where amphibole begins to break down and yield water for solution in a $\mathrm{H}_{2} \mathrm{O}$-undersaturated liquid.

Combining Figure 5 with the extrapolation in Figure 3 gives Figure 6 as an isopleth for gabbroic material in the presence of $0.1 \%$ wa- 


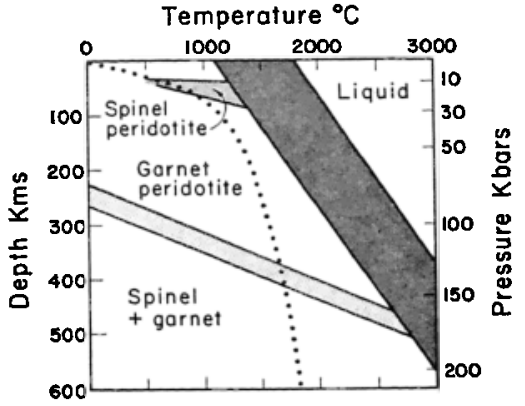

Fig. 2. Schematic phase diagram for peridotite. The melting interval is extrapolated from Ito and Kennedy [1967]. Subsolidus phase transformations are based on reviews by Ringwood [1969b] and Wyllie [1970]. Dotted ocean geotherm is from Figure 1.

ter. A similar isopleth is given in Figure 7 for peridotite-water based on preliminary data for the peridotite-water solidus and the synthesis field of amphibole in the peridotite-water system [Kushiro, 1970].

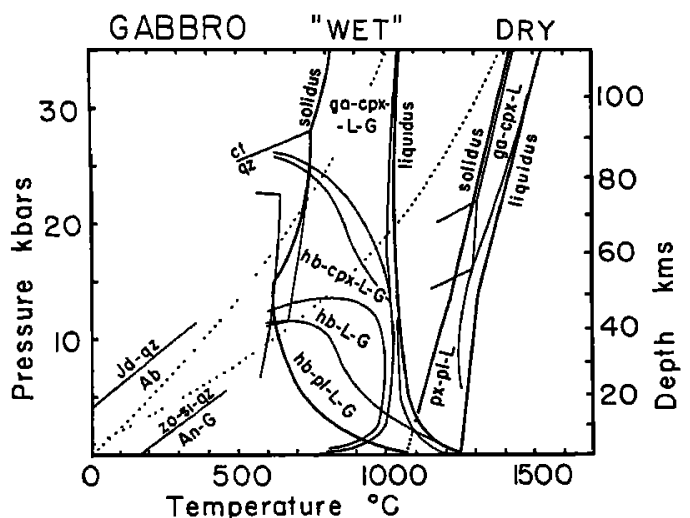

Fig. 4. Experimentally based phase relationships in gabbro [brsed on Cohen et al., 1967, and Green and Ringurood, 1967] and gabbro in the presence of excess water (unpublished data by Lambert and Wvllie: see Lambert and Wullie $[1968,1970 a, b]$, Hill and Boettecher [1970]). The interval for the coexistence of amphibole ( $\mathrm{hb}$ ) and garnet (ga) is probably too narrow. because of the reluctance of garnet to nucleate; with seeded runs, the garnet curve would probably be determined at lower temperatures. Dotted lines are the geotherms $b$ from Figure 1. Abbreviations: ga, garnet; $c p x$, clinopyroxene; $p x$, pyroxene; pl, plagioclese; hb, amphibole; qz, quartz; ct, coesite; Jd, jadeite; $A b$, albite; zo, zoisite; si, sillimanite; $\mathrm{An}$, anorthite; I, liquid; G, gas or vapor phase, aqueous. The presence of epidote or zoisite, and sillimanite or kyanite, was suspected in highpressure runs, but not proved.

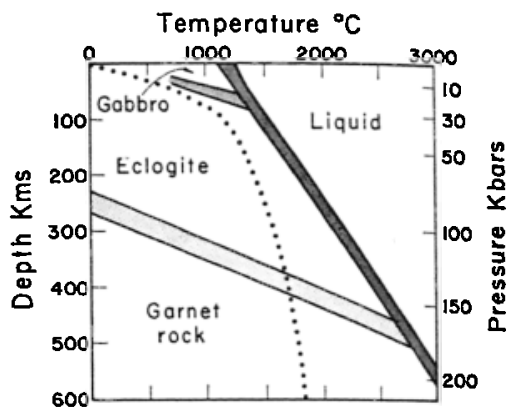

Fig. 3. Schematic phase diagram for gabbroic material. The melting interval is extrapolated from Cohen et al. [1967] and Green and Ringwood [1967]. Gabbro-eclogite transformation is from Green and Ringwood [1967] and Ito and Kennedy [1970]. Eclogite-garnet rock transformation is assumed to be in the same position as the corresponding transformation in Figure 2.

In Figures 6 and 7 , the subsolidus phase transformations are the same as in Figures 3 and 2, respectively. The melting intervals are in two parts; the dark-shaded bands correspond closely to the dry melting intervals, and the lightshaded bands show where there is a trace of silicate liquid. These latter bands show where incipient melting occurs in the presence of traces of water. Notice the curve labeled $\mathrm{Hb}$, for am-

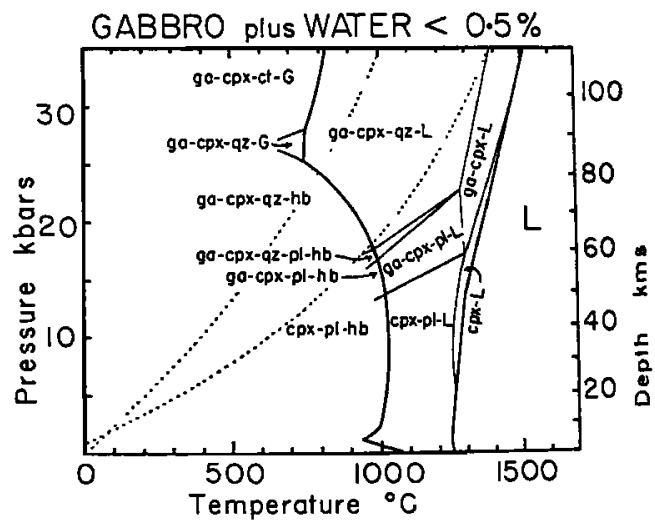

Fig. 5. Estimated isopleth for gabbro in the presence of a small proportion of water, $<0.5 \%$ by weight, based on results in Figure 4 [see Lambert and Wullie. 1970b: Wullie. 19701. The solidus is the briakdown curve for amphibole. whirh should be at somewhat higher temperatures under these water-deficient conditions than in Figure 4. Notice the subsolidus transition from amphibole-gabbro to amphibole-quartz eclogite. Dotted lines are geotherms $b$ from Figure 1 . Abbrevitions are as in Figure 4. Compare Figure 6. 


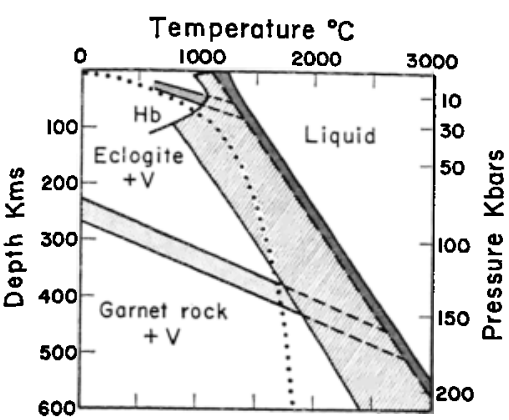

Fig. 6. Schematic isopleth for gabbro in the presence of $0.1 \%$ water, based on Figure 3 and extrapolation from Figure 5. The melting interval consists of two parts: the light-shaded band represents incipient melting, and the dark-shaded band is equivalent to normal melting as in Figure 2.

phibole breakdown; within these curves, all the mer is contained within the minerals. I assume srbitrarily in Figures 6 and 7 that the solidus ith water present becomes parallel with the dry solidus at pressures corresponding to depths greater than about $200 \mathrm{~km}$. Figures 2, 3, 6, and 7 are schematic, but there is little variation possible in the general pattern of phase relationships depicted.

The occurrence of phlogopite in peridotite mantle could extend the vapor-absent region to depths probably in the range 150 to $200 \mathrm{kms}$.

Mineral facies in the upper mantle. Figure 8 shows patterns for the petrology of hypothetical mantle sections composed of either peridotite or eclogite with a trace of water present, in two different environments. These are derived by following the shield and oceanic geotherms ( $b$ in Figure 1) through the schematic phase diagrams in Figures 6 and 7. The geotherms pass through the intervals of incipient melting. Therefore, a trace of interstitial liquid exists in the depth zones where the geotherms exceed the solidus curves, as indicated by the shaded bands in Figure 8. The shield geotherm is at a lower temperature, so the zone of ineipient melting is narrower. If the mantle is dry, then no melting occurs and only the subsolidus sequence of mineral facies is developed (compare Figures 2 and 3 ).

Lambert and Wyllie [1968, 1970a and b], using results in Figures 4 and 5, interpreted the low-velocity zone of the upper mantle in terms of incipient melting in the presence of traces

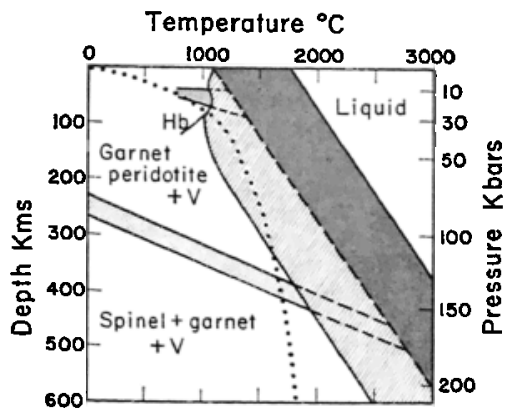

Fig. 7. Schematic isopleth for peridotite in the presence of $0.1 \%$ water, based on Figure 2, experimental data by Kushiro [1970] for excess water studies, and by analogy with Figure 6 . If phlogopite is present, its stability limit would extend to higher temperatures than the $\mathrm{hb}$ line (remaining below the dry peridotite solidus [Modreski and Boeltcher, 1970] before curving back to intersect the wet solidus at a presssure of $50 \mathrm{~kb}$ or more.

of water. They listed several possibilities for downward termination of the low-velocity zone; it is here accomplished by passage of the geotherm through the solidus at depth. The amount of interstitial liquid produced is very small, and almost a direct function of water content (see Figure $9 B$ ); it does not vary significantly through wide variations in temperature and depth. For a given water content, the amount of liquid in peridotite is much less than in eclogite. The thickness of the shaded zones with interstitial liquid in Figure 8 vary with the geotherm, and thus with the tectonic environment, and the distribution of peridotite and eclogite in the mantle also affects its position. The versatility of this model for the low-velocity zone is one of its attractive features.

The production of liquid by the presence of water is likely to change the position of the geotherm used in Figures 6 and 7, which in turn would change the sequence of mineral facies in Figure 8 . This procedure of using extrapolated experimental data and arbitrarily selected geotherms is intended only to show patterns for the petrology of the mantle; specific temperatures and depths can be modified as required by the acquisition of extended and improved theoretical and experimental data.

\section{Magmas in the System Peridotite-Water}

The most reasonable model for magma generation involves the diapiric uprise of mantle 

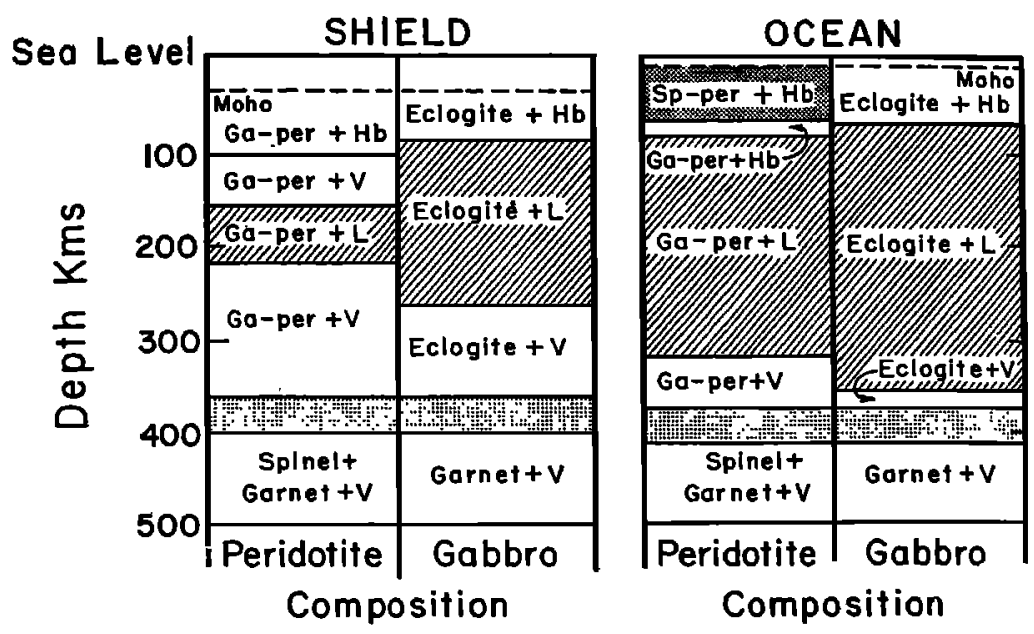

Fig. 8. Schematic sections through the upper mantle in two different tectonic environments, for mantle material composed of either peridotite or eclogite, in the presence of traces of water. These were determined by following geotherms through the mineral facies in Figures 6 and 7. Shading has same meaning as in Figures 6 and 7. The thickness of the zone of incipient melting depends on both environment (geotherm) and composition. This zone is equated with the seismic low-velocity zone.

material [Green and Ringwood, 1967]. The physical behavior of partially melted mantle depends on the amount of liquid present, and the variation in liquid composition through the melting interval is a significant factor in petro-

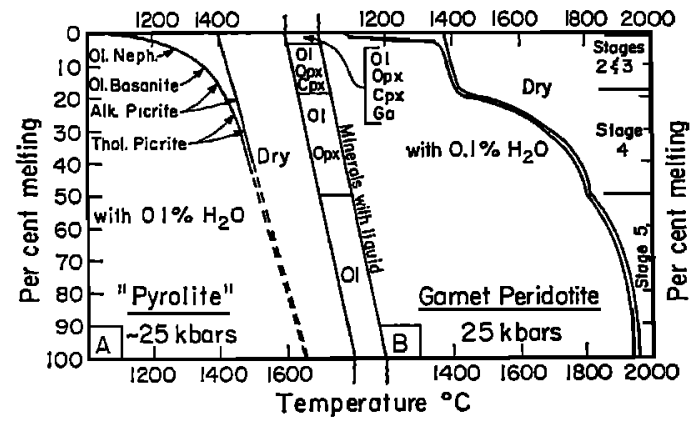

Fig. 9. Fusion curves for peridotite dry, and in the presence of $0.1 \%$ water, showing the percentage liquid produced at successive temperatures above the solidus, and the minerals coexisting with the liquid in different parts of the melting interval. (A) Dry curve from Green and Ringwood [1967]; curve with $\mathrm{H}_{2} \mathrm{O}$ and estimated liquid compositions after Green [1970]. (B) Dry curve estimated from partial experimental data by Ito and Kennedy [1967], with stages according to O'Hara [1968]; curve with $\mathrm{H}_{2} \mathrm{O}$ contrasting with the curve in $A$, and corresponding closely to Ringwood's [1969a] estimate, except for the formation of a finite amount of liquid just above the solidus, consequent on dehydration of amphibole. genesis (Figure 9). The process that causes gravitational instability is a matter for speculgtion. One possibility is that upward migration of juvenile water from the deep mantle could operate as shown in Figures 10 and 11.

Figure $9 \mathrm{~A}$ shows a linear pattern of melting for dry mantle peridotite (pyrolite) assumed by Green and Ringwood for at least 40\% fusion. This is an idealized situation. In rock systems where the percentage of melting has actually been measured, the pattern is step-like rather than linear. The dry melting curve in Figure $9 B$ is my estimate based on the results of 1 to and Kennedy [1967], who reported little increase in liquid content in a natural peridotite between $1320^{\circ} \mathrm{C}$ and $1600^{\circ} \mathrm{C}$ at $20 \mathrm{~kb}$. This curve is similar to that suggested by O'Hara [1968], who diseussed the partition of elements between crystals and liquid in five stages of fusion, without giving temperatures. These stages are shown in Figure $9 B$. The changes in slope of the dry fusion curve are related to exchanges in the mineral assemblages coexisting with the liquid, as shown by the column between Figures $9 A$ and $B$.

Green [1970] presented a comprehensive scheme for peridotite-water in the form of petrogenetic grid that provides an internally consistent working model for igneous petro- 


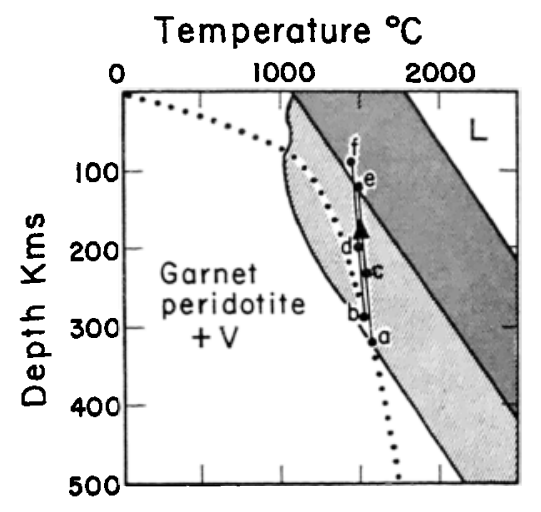

Fig. 10. Peridotite-water isopleth from Figure 7 , and dotted oceanic geotherm from Figure 1. Diapiric uprise of layer $a b$ (Figure 11A) to sucDosive positions $c d$ (Figure 11B) and ef (Figure 11C) is shown.

enesis. This is based on reconnaissance experiments in water-deficient regions with peridotites and basaltic compositions. Part of the model is shown in Figure $9 \mathrm{~A}$ by the curve showing the percentage of melting produced with $0.1 \%$ water at each temperature above the solidus, at a pressure of $25 \mathrm{~kb}$. The solidus is at $1080^{\circ} \mathrm{C}$, where amphibole breaks down (compare Figure 7). The position of this curve is etimated on the basis of experimental results, but the data and method have not been published as yet.

Green's curve for melting of peridotite with $0.1 \% \mathrm{H}_{2} \mathrm{O}$ indicates surprisingly high percentsges of liquid at subsolidus temperatures. According to the curve in Figure $9 \mathrm{~A}, 0.1 \% \mathrm{H}_{2} \mathrm{O}$ is sufficient to produce about $17 \%$ melting at the dry solidus temperature, and to dissolve all of the garnet and most of the clinopyroxene. Another value indicates $25 \%$ liquid at the dry solidus. Until this curve can be considered as securely based on experimental data, I prefer the alternative pattern shown in Figure $9 B$, which is similar to that proposed by Ringwood [1969a].

In Figure $9 B$, a finite amount of liquid is produced within a few degrees of the solidus where hornblende breaks down (contrast Figure 24 and Ringwood [1969a]), and very little sdditional liquid is produced until the temperature closely approaches that of the dry solidus; at higher temperatures it follows the dry curve, rather than approaching it asymptotically as

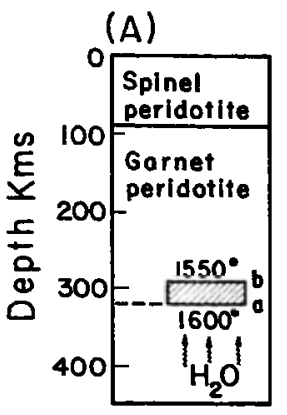

(B)

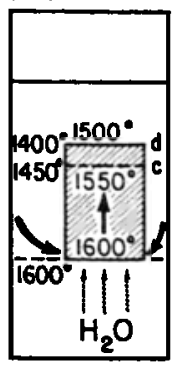

(C)

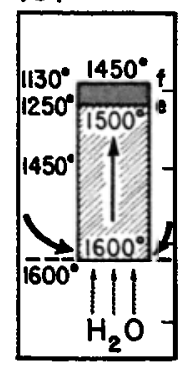

Fig. 11. Schematic mantle sections showing the diapiric uprise of layer $a b$ at the base of the low-velocity zone into successive positions $c d(B)$ and $e f(C)$ on the adiabatic curves ace and bdf $(B)$ Figure 10. Water migrating from the deep mantle increases liquid present in layer $a b$, causing diapiric uprise from the base of the low-velocity zone, and basaltic magma generation toward the top of the zone.

indicated by Green's curve between about 30 and $40 \%$ melting. I have not attempted to estimate actual percentages of melting because I do not have adequate data, and the percentages guessed are simply to illustrate a pattern that contrasts with Green's pattern. Distinction between these two patterns is important, because the amount of interstitial liquid produced by traces of water below the dry melting temperature affects markedly the physical properties of the mantle and the prospects that the liquid can escape from its host for independent uprise as a magma.

The composition of the liquid produced is in dispute. From experimental studies, Green [1970] inferred that highly alkaline, undersaturated liquids could form by partial melting of mantle peridotite in the presence of water, and Figure $9 \mathrm{~A}$ shows the compositions of the liquids developed at successive stages of partial fusion. From experiments in synthetic systems, Kushiro [1970] concluded that the liquids are andesitic or tholeiitic in composition.

Kushiro [1970] studied the composition of liquids coexisting with synthetic forsterite, orthopyroxene, clinopyroxene, and garnet at $20-\mathrm{kb}$ pressure both dry and with excess water. The dry liquid is nepheline-normative, and the $\mathrm{H}_{2} \mathrm{O}$ saturated liquid is quartz-normative. Probe measurement of the glass confirms that the latter liquid composition was andesitic (Kushiro, personal communication, 1970). 
Green [1970] concluded that both sets of experimental data were correct, but he described preliminary experiments suggesting that at 22.5 $\mathrm{kb}$ the conclusions from Kushiro's synthetic systems cannot be extrapolated to a typical basalt. He doubted that a quartz-normative tholeiitic or andesitic liquid could coexist with olivine at water pressure greater than $10 \mathrm{~kb}$. Kushiro's results show that in the absence of hydrous minerals (e.g. amphibole) the first liquid produced is andesitic, and $\mathrm{H}_{2} \mathrm{O}$-saturated. The amount of andesitic liquid produced depends on the water content; with continued fusion in the vapor-absent region, the liquid compositions trend toward nepheline-normative.

The apparent conflict of interpretation between Green and Kushiro may be resolved when all the variables are considered and their effects adequately determined. In different parts of a petrogenetic grid such as that proposed by Green, we have partial fusion of the following assemblages, each of which may involve a liquid of different composition: (1) anhydrous minerals only, with vapor; (2) anhydrous and hydrous minerals, with vapor; (3) anhydrous and hydrous minerals, with no vapor. In compositions 1 and 2 , the first liquid is $\mathrm{H}_{2} \mathrm{O}$-saturated, but in 3 the first liquid is $\mathrm{H}_{2} \mathrm{O}$-undersaturated. Figure 7 shows that a given fixed composition in the system peridotite- $\mathrm{H}_{2} \mathrm{O}$ may change from condition 3 to condition 1 as a simple function of depth. Robertson and Wyllie [1971] have reviewed these factors in the water-deficient region of rock-water systems.

\section{DIAPIRIC UpRISE FROM THE BASE OF THE Low-VeLOCITY ZONE}

It has often been suggested that magma generation begins with diapiric uprise from the upper level of the low-velocity zone. I propose that uprise may begin at the base of the lowvelocity zone, at depths of the order of 300 $\mathrm{km}$, and that uprise may be triggered by the outward migration of water from within the deep mantle. The process is illustrated in Figures 10 and 11.

Figure 10 shows the isopleth for peridotite with $0.1 \% \mathrm{H}_{2} \mathrm{O}$, from Figure 7. The dotted curve is a standard suboceanic geotherm from Figure 1. Figure 11 shows three schematic sections through the mantle representing successive stages in time that can be correlated with
Figure 10. The heavy dashed line at about 320 $\mathrm{km}$ is the bottom of the low-velocity zone, marked by $a$ in Figure 10. The low-velocity zone between $a$ and a depth of about $90 \mathrm{~km}$ contains interstitial liquid (not represented in Figure 11).

If water migrates upward along the geotherm in Figure 10, it reaches the low-velocity zone at $a$, and the water content of a layer such as $a b$ increases; the increase of water causes more melting in this layer, approximately in proportion to the amount of water added. The increased melting lowers the density and viscosity of the layer relative to the surrounding mantle, and it tends to rise as shown in Figure $11 B$ [Ramberg, 1967]. It rises adiabatically (Figure $10)$, and when the layer $a b$ reaches the position $c d$ it is about $100^{\circ} \mathrm{C}$ hotter than the surrounding mantle. Continued uprise carries it through the level near the dry solidus, where significant melting occurs (see Figure $9 B$ ), and at ef magma generation occurs in the normal way and subsequent events follow the dry model of Green and Ringwood [1967].

\section{Petrology of the Mantle Beneath THE OCEANS}

Figure 8 shows that the petrology of the mantle varies with temperature distribution as well as with composition. Horizontal temperature gradients produce horizontal petrological variations. Oxburgh and Turcotte [1968] considered the problem of mantle convection, and presented a steady-state distribution of isotherms beneath an ocean ridge, computed on the basis of a boundary layer theory, and assuming a constant viscosity, independent of temperature. They concluded that, although their assumed viscosity relations were certainly wrong, the provisional agreement between the model and natural phenomena suggests that the simplifying assumptions had not too great an effect. There is a mushrooming isotherm distribution associated with the upper ascending limb beneath the mid-oceanic ridge. Actual temperatures here would be decreased by upward transfer of heat by basaltic magmas.

The general pattern of the petrology of the upper mantle beneath the ridges and oceanic lithosphere can be determined from this model for temperature distribution and the schematie phase diagrams in Figures 6 and 7; the results 
are shown in Figures 12 and 13. Each point in the mantle section is defined by a specific pressure (depth) and temperature, and the phase assemblage for a given material at each point can be determined from the appropriate phase diagram, Figure 6 or 7 .

Figure 12 shows the distribution of phase assemblages for a mantle composed of peridotite with a trace of water, and Figure 13 shows the phase assemblages produced in gabbroic material with a trace of water. The layered sequence for mantle some distance from the ridge is similar to that summarized in Figure 8. The presence of a trace of water produces a zone of incipient melting, which is equated with the low-velocity zone. Material of gabbroic composition exists as eclogite. The low-velocity zone increases in thickness considerably near the ridge crest, extending downward to the level of the olivinespinel transition.

There is a large zone of partial melting where the temperature exceeds the dry solidus of peridotite, and gabbro in most of the corresponding zone in Figure 13 is completely melted. The zone is more than $400 \mathrm{~km}$ wide and $200 \mathrm{~km}$ thick. Oxburgh and Turcotte noted that only mantle material ascending along stream lines

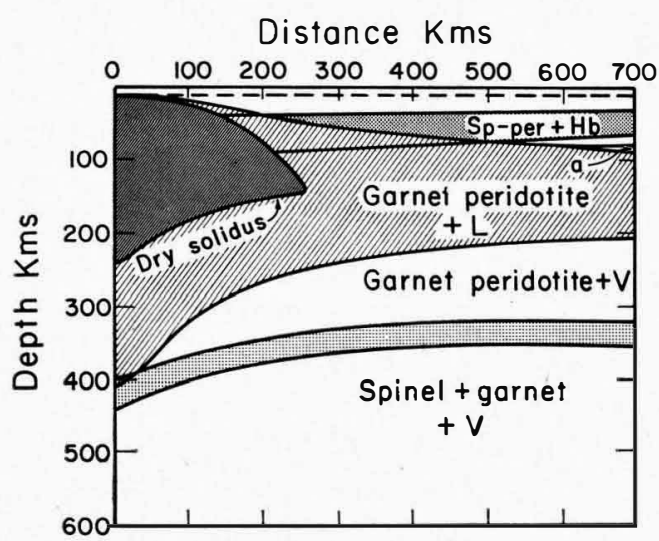

Fig. 12. Schematic section showing the petrology of peridotite with traces of water in the suboceanic mantle, extending from the crest of a mid-oceanic ridge. Far from the ridge, the section is similar to one in Figure 8. The area $a$ is for garnet peridotite plus vapor. The shading has the same significance as in Figure $\mathbf{7}$ and 8 . Each point in the mantle section is defined by a specific pressure (depth) and temperature, using Oxburgh and Turcotte's [1968] isotherms as basis, and the appropriate phase assemblages are plotted accordingly from Figure 7. within $100 \mathrm{~km}$ of the plume center would pass through this fusion zone, and that this material then forms the upper $130 \mathrm{~km}$ of the horizontal limb. If all the basaltic magma generated within the fusion zone escapes to the surface at or near the ridge, then this $130-\mathrm{km}$ layer would be composed of residual peridotite. On the other hand, if some of the interstitial magma crystallizes as it is transported laterally through the upper boundary of the fusion zone, we have to consider phase assemblages in the upper mantle for material of basaltic composition.

Figure 13 shows that basaltic magma emerging from the fusion zone above about $80-\mathrm{km}$ depth crystallizes as gabbro, and that below $100 \mathrm{~km}$ it crystallizes as eclogite. Lateral transportation of the lithosphere causes cooling of the gabbro, and if equilibrium is maintained the gabbro is transformed into eclogite through a wide zone of garnet granulite [Ito and Kennedy, 1970]. This illustrates the dynamic model for the suboceanic mantle proposed by Press [1969]. The low density layer of gabbro and garnet granulite exhibits a general pattern similar to that required by Talwani et al. [1965] for

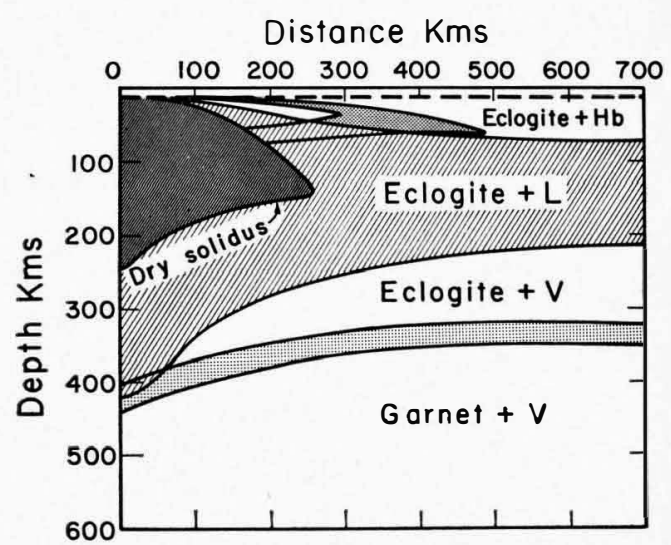

Fig. 13. Schematic section showing the petrology of a hypothetical suboceanic mantle composed of eclogite with traces of water, exterding from the crest of a mid-oceanic ridge. Far from the ridge, the section is similar to one in Figure 8 . This shows mineral facies for mantle layers or pockets of eclogite, with traces of water. The shading has the same significance as in Figure 6 and 8. This is based on Oxburgh and Turcotte's [1968] isotherms. Notice the shallow (less than $100 \mathrm{~km}$ ) lens of gabbro and garnet granulite extending out to about $500 \mathrm{~km}$ from the ridge crest before the temperature cools sufficiently to produce eclogite (under equilibrium conditions). 


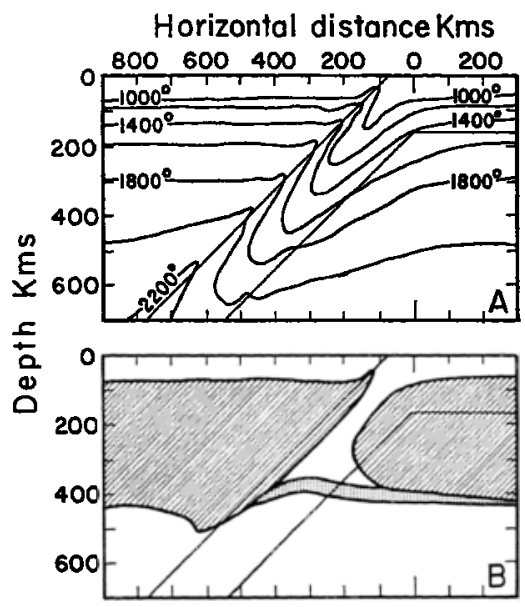

Fig. 14. Schematic sections through the mantle and slab of lithosphere in mantle beneath an island arc. The lithosphere, $160-\mathrm{km}$ thick, dips at $45^{\circ}$ from the axis at $0 \mathrm{~km}$. (A) Isotherms computed by Minear and Toksöz [1970], according to their Figure 9, which takes into account shearstrain heating along the edges of the lithosphere slab. (B) Petrology of the mantle section, assuming peridotite with traces of water (Figure 7) and the temperature distribution in $A$. The shaded zone shows incipient melting, interrupted by the slab. Uprise of the olivine-spinel transformation zone within the cold slab is shown. The corresponding diagram for gabbroic material is very similar. Normal fusion temperatures for the generation of basaltic magmas are not reached anywhere according to this temperature distribution, and according to the extrapolated solidus from Figure 1.

the structure of mid-oceanic ridges. Although modification of the temperature distribution and experimental determination of the phase diagrams will change the details in Figures 12 and 13 , the general pattern is probably realistic.

\section{Petrology of the Mantle Beneath IsLAND ARCs}

The concept of plate tectonics requires that the lithosphere extend down into the mantle beneath island arcs [Isacks et al., 1968], as shown schematically in Figure 14. Minear and Toksöz [1970] used a quasi-dynamic scheme and a finite difference solution of the conservation of energy equation to determine the effects of several factors on the temperatures in a downgoing slab. Thermal regimes were calculated for a $160-\mathrm{km}$-thick slab downwarping at $45^{\circ}$ to the horizontal, with the complexity of the physical

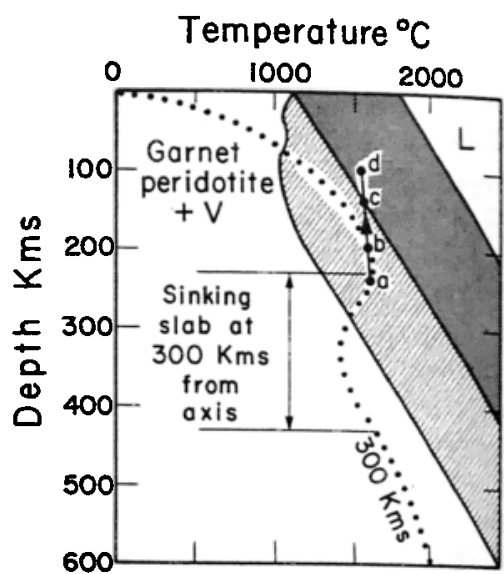

Fig. 15. Peridotite-water isopleth from Figure 7 , and the position of the sinking slab in the mantle at $300 \mathrm{~km}$ from the axis in Figure $14 A$. The dotted line is the geotherm for this position, taken from the isotherms in Figure 14A. Temperature decreases within the slab. This shows the diapiric uprise of layer $a b$ (see Figure 16B) along an adiabat to the level $c d$ (Figure $16 C$ ), where basaltic magma is generated.

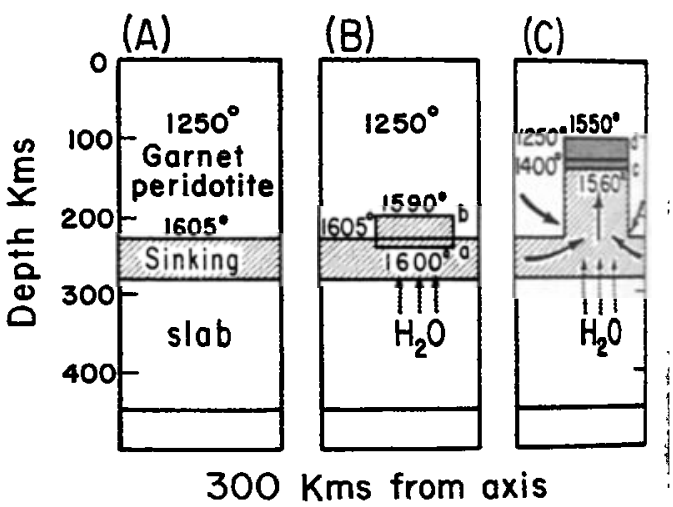

Fig. 16. Schematic mantle sections at a dis tance of $300 \mathrm{~km}$ from the axis in Figure 14 showing diapiric uprise of layer $a b(B)$ to level $c d(C)$ along the adiabat shown in Figure 15: $(A)$ The sinking slab with interstitial water in a dry mantle of garnet peridotite. Only the upper part of the slab has a temperature high enough even for incip ient melting. $(B)$ Migration of water from the slab into layer $a b$, across the upper boundary of the slab, increases the extent of partial melting, lesaing to diapiric uprise of slab and adjacent mantle as in $C$. (C) Basaltic magma is generated layer $c d$. 
model being increased in a series of steps to demonstrate the effects of the various heat-genenting processes and the spreading rate. Figure 144 shows the distribution of isotherms taken from their Figure 9, which assumes a 1-cm/ year spreading velocity, shear-strain heating of $1.6 \times 10^{-4} \mathrm{erg} / \mathrm{cm}^{3} \mathrm{sec}$ along the top edge of the slab, and $1.0 \times 10^{-5} \mathrm{erg} / \mathrm{cm}^{3}$ sec along the ends and bottom, and no contribution from phase changes or adiabatic compression. The dominant pattern is one of isotherms depressed deeply into the mantle. The zone of shear-strain heating with temperatures greater than those in normal mantle is less than $30-\mathrm{km}$ wide above $200 \mathrm{~km}$, and the greatest temperature increases accur at depths less than $100 \mathrm{~km}$.

Each point in Figure $14 A$ is specified by a temperature and pressure, and assuming a composition of peridotite with $0.1 \%$ water, the uppropriate phase assemblage can be assigned to each point from Figure 7 ; the results are shown in Figure $14 B$. No melting occurs in peridotite (or in gabbro or eclogite) in this manthe section in the absence of water, but, given 8 trace of water, incipient melting occurs in the shrded zone. If this layer does correspond to the low-velocity layer, as was suggested in conrection with Figure 8, then Figure $14 B$ suggests thet the layer is not continuous beneath island ares. Upward migration of the olivine-spinel transition zone within the cool slab is shown.

Magma may be generated beneath an island are system in three ways: (1) The oceanic crust at the surface of the lithosphere, including silioous and water-bearing sediments, could be partially fused either by thermal conduction from the mantle, or by frictional heating, producing the calc-alkaline series [Hamilton, 1969; Oxburgh and Turcotte, 1970]. (2) Dehydration of the lithosphere and upward migration of water into hotter mantle overlying the slab could produce partial melting in the mantle, yielding intermediate and acid magmas for andesites and batholiths [McBirney, 1969]. (3) Diapiric uprise of solid peridotite or eclogite mder adiabatic conditions may oceur from the whe of frictional heating, leading to magma meration according to the Green and Ringmod [1968] model.

Figure 15 shows a geotherm at a distance of $300 \mathrm{~km}$ from the axis in Figure 14, and the depth interval occupied by the sinking slab at this distance. The temperature decreases within the slab, and there is a temperature maximum at or within a small layer $a b$ across its upper boundary. Figure 15 also shows the isopleth for peridotite in the presence of a trace of water, transferred from Figure 7. If we assume a mantle containing no water, the slab is bounded by dry garnet peridotite, with the potential for incipient melting above the slab if water is added (compare Figures $14 B$ and 15). If we assume that water is carried down into the mantle in the lithosphere slab, we have the situation depicted in Figure $16 \mathrm{~A}$ for a vertical profile at a distance of $300 \mathrm{~km}$ from the axis. The position of the sinking slab is shown, and the upper part of this slab contains interstitial silicate liquid (compare Figures $14 B, 15$, and 16A). If water migrates from the sinking slab into the overlying mantle, this causes incipient melting in the layer $a b$, as is shown in Figure $16 B$ (compare Figure 15). Influx of water from the slab into this layer increases the percentage of liquid present, decreases the density and viscosity, and facilitates diapiric uprise as shown in Figures 15 and $16 C$ by the path $a b c d$. This process would produce basaltic magmas from peridotite, or andesite from eclogite, at depths considerably above the Benioff zones. If water is abundant, liquids of intermediate composition may be generated in similar fashion from peridotite; we have seen that the compositions of liquids depend on a number of variables.

\section{Discussion}

Future correlation of the observed products of volcanoes with the compositions of liquids from various crystalline materials under known experimental conditions should permit us to locate the sources of specific magmas beneath island arcs and beneath ocean ridges. This would provide invaluable fixed points in terms of depths (pressures) and temperatures for many geophysical calculations and models, such as the computed temperature distribution in Figure 14A. This in turn would place limits on assumed physical properties of mantle materials. The way in which petrology, geophysics, and experimental petrology and geophysics are coming to be mutually dependent is very heartening. Until more precise data are available, we will have to be satisfied with general patterns such as Figures $8,12,13$, and $14 B$, based on extrapo- 
lated experimental data (Figures 6 and 7) and possible temperature distributions such as Figure 14A. These provide insight into processes, and guidelines for further experiments.

Acknouledgments. I thank the National Science Foundation for grant GA-15718 and the Advanced Research Projects Agency for support from grant SD-89.

\section{REFRRENCES}

Clark, S. P., and A. E. Ringwood, Density distribution and constitution of the mantle, Rev. Geophys., 2, 35, 1964.

Cohen, L. H., K. Ito, and G. C. Kennedy, Melting and phase relations in an anhydrous basalt to 40 kilobars, Amer. J. Sci., 265, 475, 1967.

Green, D. H., Compositions of basaltic magmas as indicators of conditions of origin: Application to oceanic volcanism, Phil. Trans. Roy. Soc. London, in press, 1970.

Green, D. H., and A. E. Ringwood, The stability fields of aluminous pyroxene peridotite and garnet peridotite and their relevance in upper mantle structure, Earth Planet. Sci. Lett., 3, 151, 1967.

Green, T. H., and A. E. Ringwood, Genesis of the calc-alkaline igneous rock suite, Contrib. Mineral. Petrol., 18, 105, 1968.

Hamilton, W., Mesozoic California and the underflow of Pacific mantle, Geol. Soc. Amer. Bull., 80, 2409, 1969.

Hill, R. E. T., and A. L. Boettcher, Water in the earth's mantle: Melting curves of basalt-water and basalt-water-carbon dioxide, Science, 16\%, $980,1970$.

Isacks, B., J. Oliver, and L. R. Sykes, Seismology and the new global tectonics, J. Geophys. Res., $73,5855,1968$.

Ito, K., and G. C. Kennedy, Melting and phase relations in a natural peridotite to 40 kilobars, Amer. J. Sci., 265, 519, 1967.

Ito, K., and G. C. Kennedy, Melting and phase relations in the plane tholeiite-lherzolite-nepheline basanite to 40 kilobars with geological implications, Contrib. Mineral. Petrol., 19, 177, 1968.

Ito, K., and G. C. Kennedy, The fine structure of the basalt-eclogite transition, Mineral. Soc. Amer. Spec. Pap. 3, 77, 1970.

Kushiro, I., Systems bearing on melting of the upper mantle under hydrous conditions, Carnegie Inst. Wash. Yr. Book 68, 240, 1970.

Kushiro, I., Y. Syono, and S. Akimoto, Melting of a peridotite nodule at high pressures and high water pressures, J. Geophys. Res., 73, 6023, 1968.
Lambert, I. B., and P. J. Wyllie, Stability of homblende and a model for the low velocity zone, Nature, 219, 1240, 1968.

Lambert, I. B., and P. J. Wyllie, Melting in the deep crust and upper mantle and the nature of the low velocity layer, Phys. Earth Planet. Int., S, 316, $1970 a$.

Lambert, I. B., and P. J. Wyllie, Low-velocity zone of the earth's mantle: Incipient melting caused by water, Science, 764, $1970 b$.

Lubimova, E. A., Theory of thermal state of the earth's mantle, in The Earth's Mantle, edited by T. F. Gaskell, p. 232, Academic, New York. 1967.

McBirney, A. R., Compositional variations in Cenozoic calc-alkaline suites of Central America Oreg. Dep. Geol. Miner. Ind. Bull., 65, 185, 1969 .

Minear, J. W., and M. N. Toksöz, Thermal regime of a downgoing slab and new global tertonics, J. Geophys. Res., 75, 1397, 1970.

Modreski, P. J., and A. L. Boettcher, The stability of phlogopite in the earth's mantle. Abstracts with programs, Geol. Soc. Amer., 2, 626, Denver, 1970.

O'Hara, M. J., The bearing of phase equilibria studies in synthetic and natural systems on the origin and evolution of basic and ultrabasic rocks, Earth Sci. Rev., 4, 69, 1968.

Oxburgh, E. R., and D. L. Turcotte, Mid-ocean ridges and geotherm distribution during mantle convection, J. Geophys. Res., 73, 2643, 1968.

Oxburgh, E. R., and D. L. Turcotte, Thermal structure of island arcs, Geol. Soc. Amer. Bull., $81,1665,1970$.

Press, F., The suboceanic mantle, Science, 165, 174, 1969.

Ramberg, H., Gravity, Deformation and the Earth's Crust, Academic, London, 214 pp., 1967.

Ringwood, A. E., Composition and evolution of the upper mantle, in The Earth's Crust and Upper Mantle, Geophys. Monograph 18, edited by P. J. Hart, p.1, AGU, Washington, D. C., $1969 a$.

Ringwood, A. E., Phase transformations in the mantle, Earth Planet. Sci. Lett., 5, 401, 1969b.

Robertson, J. K., and P. J. Wyllie, Magma generation and crystallization: Rock-water systems, with special reference to the water-deficient region, submitted to Amer. J. Sci., 1971 .

Talwani, M., X. Le Pichon, and M. Ewing. Crustal structure of the mid-ocean ridges, J. Geophys. Res., 70, 341, 1965.

Tozer, D. C., Towards a theory of thermal convection in the mantle, in The Earth's Mantle, edited by T. F. Gaskell, p. 327, Academic, New York 1967.

Wyllie, P. J., Ultramafic rocks and the upper mantle, Mineral. Soc. Amer. Spec. Pap. S, 3, 1970.

(Received August 11, 1970.) 